\title{
PERICARDITIS AND COMPLETE HEART BLOCK DURING THIOURACIL THERAPY
}

\author{
BY \\ C. W. CURTIS BAIN \\ From the Harrogate General Hospital \\ Received October 12, 1944
}

Thiouracil has been used with success in many cases of thyrotoxicosis (Himsworth, 1944). Reported complications include agranulocytosis, rashes, and fever (Astwood, 1943). In the following case the drug had to be stopped on account of a severe cardiac reaction.

\section{CASE History}

Mrs. G. W. was first admitted to hospital in 1932 at the age of 21 with a diagnosis of thyrotoxicosis. Both lobes of the thyroid were uniformly enlarged, and a fortnight after admission the right lobe and the isthmus were removed. During convalescence she developed nasal catarrh with fever, and Mr. Pavey-Smith reported that both tonsils were infected. At the same time the histological report on the excised portion of the gland revealed a simple colloid goitre. Nevertheless, a month later the left lobe was removed and the tonsils were left in situ. Following this she kept in good health until 1942, when she began to suffer from a recurrence of tonsillitis and from symptoms of thyrotoxicosis. In February 1944 she was seen by Mr. Pavey-Smith at Ripon -Hospital, who found the tonsils to be flat and red, with some pus in the crypts. In view of the symptoms of thyrotoxicosis he advised admission to Harrogate for investigation. Unfortunately this took place during his absence owing to illness, and his house surgeon, unable to find the evidence of tonsillar sepsis, referred her to the surgeon, who thought that a further thyroidectomy might be needed, but desired first to know if she might be a suitable case for thiouracil.

On examination she was flushed and anxious with a fine tremor. There was slight exophthalmos. The heart was not enlarged and there were no murmurs. The basal metabolic rate was +27 . The blood sedimentation rate was normal. She had never suffered from rheumatism.

Thiouracil was started on April 14 in doses of $0 \cdot 2 \mathrm{~g}$., five times daily. below.

Further estimations of the white cells and of the basal metabolic rate were made as shown

\begin{tabular}{c|c|c|c}
\hline Date & Basal metallic rate & $\begin{array}{c}\text { Leucocytes } \\
\text { per cub. mm. }\end{array}$ & $\begin{array}{c}\text { Polymorphs } \\
\text { per cub. mm. }\end{array}$ \\
\hline $11 / 4 / 44$ & +27 & 11,000 & 6,000 \\
$17 / 4 / 44$ & +24 & 9,000 & 5,500 \\
$20 / 4 / 44$ & - & 9,000 & 4,500 \\
$21 / 4 / 44$ & +22 & 12,000 & 8,000 \\
$26 / 4 / 44$ & - & 13,000 & 9,500 \\
$29 / 4 / 44$ & - & 27,000 & 22,000 \\
\hline
\end{tabular}

On April 21 she complained of a tight feeling across the front of her chest: otherwise she felt much better. Screen examination on April 24 showed that the transverse cardiac diameter was not increased although there was a slight fullness in the pulmonary area.

On April 25 her temperature was $100^{\circ} \mathrm{F}$. There were no physical signs and it was decided 
to continue thiouracil since she had had a similar spike before the drug was started. On the following day the temperature was $101^{\circ} \mathrm{F}$; the next day it was $102^{\circ} \mathrm{F}$., and she now complained of rheumatic pains in the legs. At 4.30 a.m. on April 28 she was seized with a severe pain in her chest which radiated up to the neck and to both shoulders. The pain was worse on inspiration. Thiouracil was stopped. When examined at $10.0 \mathrm{a} . \mathrm{m}$. she was sitting propped up and was in considerable pain. The heart sounds were sharp and the rate was slower than would be expected with a temperature of $100^{\circ} \mathrm{F}$. Morphia, 1/4 of a grain, was given and a cardiogram was taken (Fig. 1).

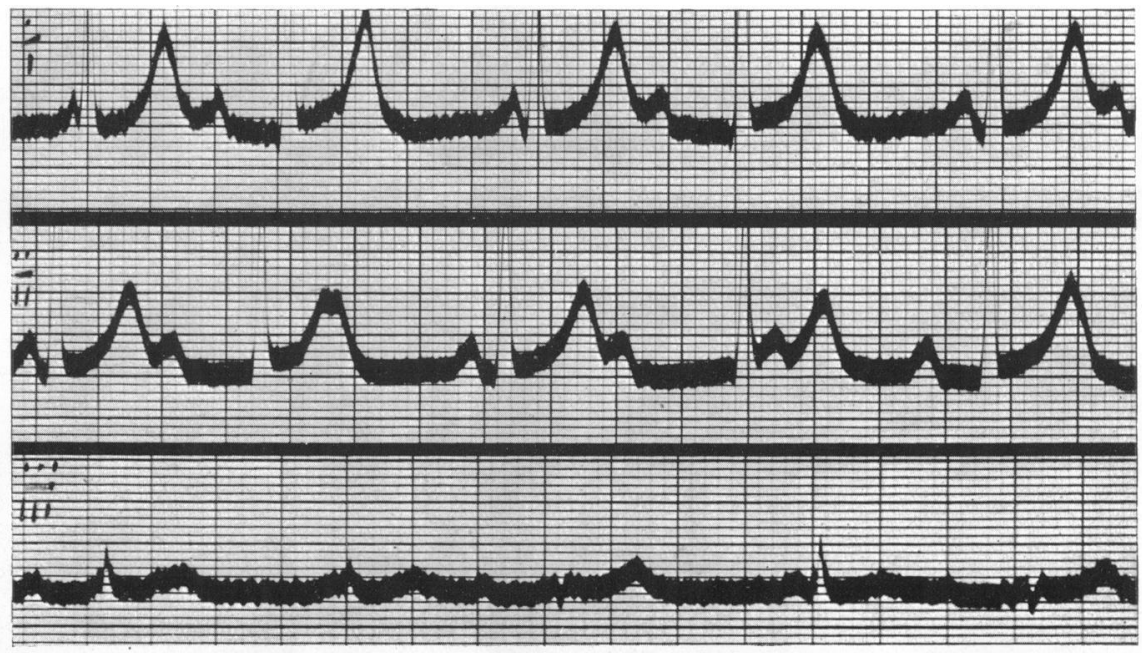

Fig. 1 (28/4/44).-Complete A-V dissociation. Auricular rate, 130; ventricular rate, 84. (Reduced to 4/5ths.)

On May 1 a widespread pericardial friction sound was audible. Slight jaundice was present (the Van den Berg showing a weak immediate positive reaction with 0.8 units of bilirubin), but the liver was not enlarged nor tender. All her pains were much improved. By May 4 pericardial friction was much less obvious, and on May 11 traces only were audible at the base of the heart.

The first cardiogram (28/4/44) (Fig. 1) shows complete A-V dissociation with an auricular rate of 130 and a ventricular rate of 84 . In Fig. 2 (29/4/44) there is elevation of the S-T

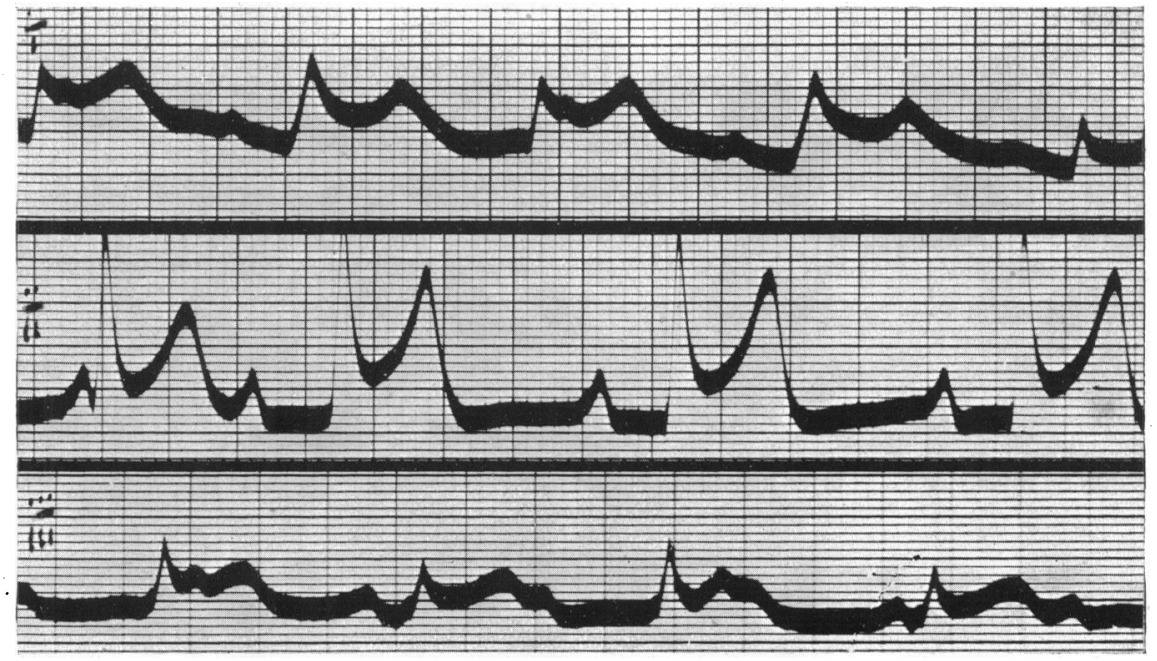

FIG. 2 (29/4/44).-Elevation of S-T junction in all leads. Complete dissociation present in leads I and II. Dissociation changes to $2: 1$ heart block in latter part of lead II. (Reduced to 4/5ths.) 
segment in all leads. Complete dissociation persists in leads I and III, but in lead II the dissociation gives place to $2: 1$ heart block in the latter half of the tracing. In Fig. $3(1 / 5 / 44)$ latent heart block is present with a P-R interval of $0.23 \mathrm{sec}$., and $\mathrm{T}$ is inverted in all leads, still with a raised S-T segment in lead II. Subsequent cardiograms show a gradual return to normal.

Subsequent course. The patient was re-examined in November and in January 1945. There was only a soft apical systolic murmur between the heart sounds. The cardiac silhouette presented the same appearance as in April. She is now back at work.

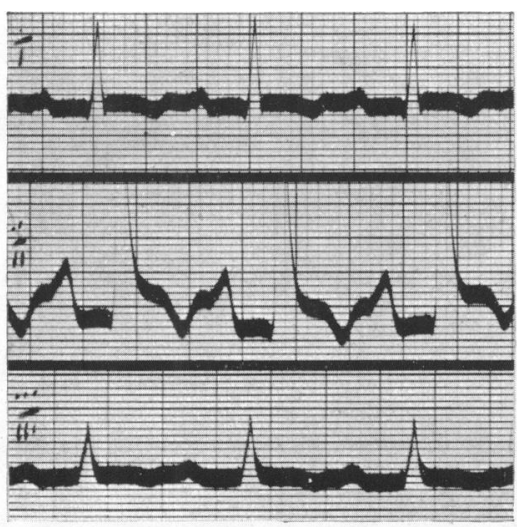

FIG. $3(1 / 5 / 44)$.- - Latent heart block (P-R, $0 \cdot 23 \mathrm{sec}$.).-Inversion of $\mathrm{T}$ in all leads with high take-off from $\mathrm{R}$ in lead II. (Reduced to $2 / 3$ rds.)

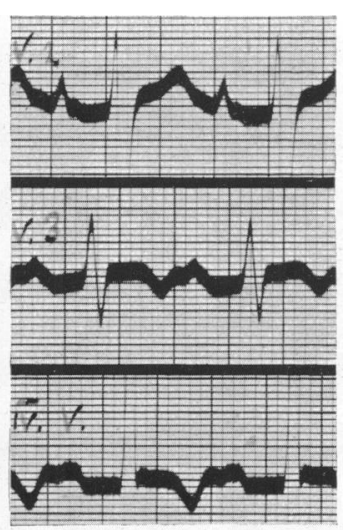

\section{F.}

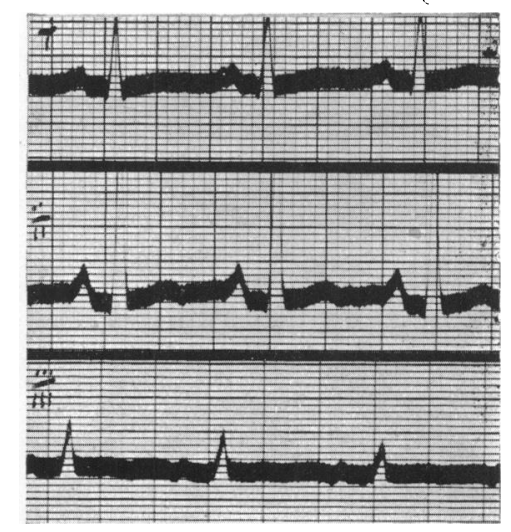

FIG. $4(11 / 5 / 44)$.-Flattened $\mathrm{T}$ waves, otherwise normal. (Reduced to 2/3rds.)

\section{Discussion}

It will be conceded this case was hardly suitable for thiouracil therapy. Had the notes of the previous admission or the recent report of the ear, nose, and throat surgeon been available, the drug would not have been given. But no cardiovascular complications have yet been recorded from thiouracil. Fever may occur from the eighth to tenth day and it does not seem by itself to be dangerous (Johnston, 1944).

Although the patient was 33 years of age and had never previously suffered from rheumatism, the attack resembled most an acute rheumatic carditis. On the third day of fever she had pain in the limbs, and next morning she had severe pain in the chest. With the onset of the precordial pain the pulse rate fell from 120 to 90 and complete A-V block was recorded a few hours later. On the following day the cardiogram showed changes suggestive of pericarditis and widespread friction became audible soon after. On the other hand, at no time was there an acute tonsillitis nor did she complain of a sore throat. Salicylates were not given, yet the fever subsided on the day that thiouracil was stopped, and her pain went two days later. It seemed as if the attack was caused in some way by thiouracil. No valvular lesion developed during the succeeding eight months.

It would appear as if caution should be exercised in administering thiouracil in the presence of a septic focus.

\section{SUMMARY}

A case of pericarditis with complete heart block is described in a patient receiving methyl thiouracil for thyrotoxicosia. The tonsils were infected but there was no previous history of rheumatism.

\section{REFERENCES}

Astwood, E. B. (1943). J. Amer. med. Ass., 122, 78.

Himsworth, H. P. (1944). Proc. Roy. Soc. Med., 37, 693.

Johnston, C. R. S. (1944). Lancet, $2,42$. 